This item was submitted to Loughborough's Research Repository by the author.

Items in Figshare are protected by copyright, with all rights reserved, unless otherwise indicated.

\title{
Children's fitness testing: A feasibility study
}

PLEASE CITE THE PUBLISHED VERSION

PUBLISHER

(c) Sage

VERSION

AM (Accepted Manuscript)

LICENCE

CC BY-NC-ND 4.0

REPOSITORY RECORD

Harris, Josephine P., and Lorraine Cale. 2019. "Children's Fitness Testing: A Feasibility Study". figshare. https://hdl.handle.net/2134/4467. 
This item was submitted to Loughborough's Institutional Repository (https://dspace.lboro.ac.uk/) by the author and is made available under the following Creative Commons Licence conditions.

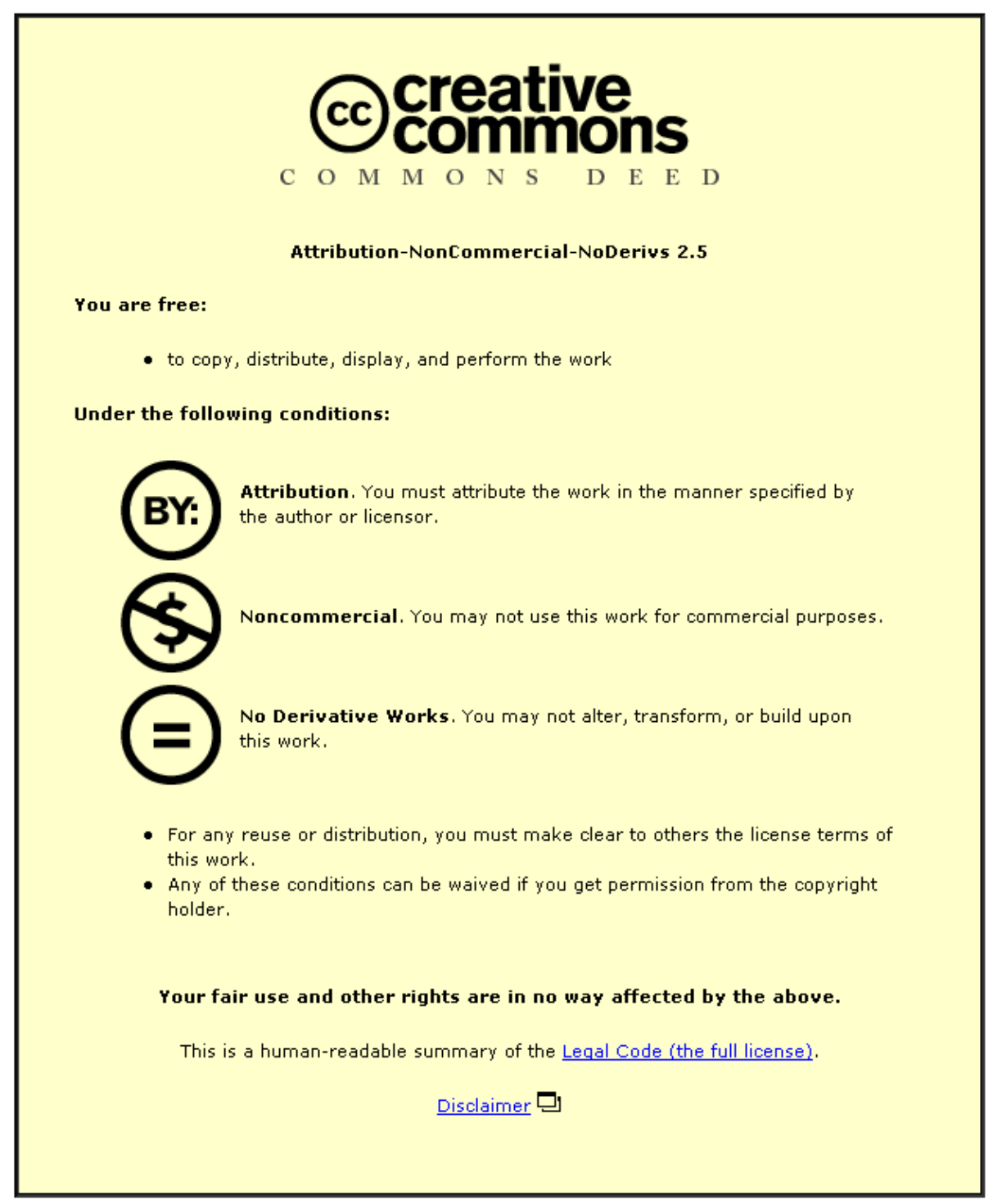

For the full text of this licence, please go to: http://creativecommons.org/licenses/by-nc-nd/2.5/ 
Title

Children's Fitness Testing: A Feasibility Study

\section{Authors}

Dr Harris, J. \& Dr Cale, L.

Institution

School of Sport and Exercise Sciences

Loughborough University

Leicestershire

England

Key words

Fitness; fitness testing; activity promotion; physical activity; children 


\section{Abstract}

Objective: This study aimed to determine whether it was necessary, cost effective and practical to investigate Welsh children's fitness levels in order to promote active, healthy lifestyles.

Design: A multi-method study comprising a comprehensive review of literature, a questionnaire survey and interviews.

Setting: This was a feasibility study commissioned by the National Assembly for Wales undertaken between October 2003 and March 2004. Method: The methodology involved a world wide literature search carried out using metalib and consultation with UK experts and stakeholders in Wales via a questionnaire $(n=35)$ and individual interviews $(n=5)$. The response rate for the questionnaire survey was $36.4 \%$.

Results: The study indicated concern amongst experts and stakeholders about Welsh children's health, fitness and activity, but also revealed a number of misconceptions about children's fitness and fitness testing. The study highlighted that the measurement of children's fitness is fraught with difficulties, including methodological limitations, the possible negative impact on some children, and the relatively weak association between children's physical fitness and health. Additionally, utilising children's fitness test data to inform policy and practice was considered problematic by the experts and stakeholders, and there was limited evidence from the literature that previously conducted large scale surveys on children's fitness have positively impacted on children's health, activity and fitness. 
Conclusion: It was concluded that a research project focusing solely on fitness testing Welsh children is neither necessary, cost effective nor practical. However, a 'lifestyle oriented' project including the monitoring of physical activity was recommended as increasing activity levels is achievable for all and the process which will lead to health gains. 


\section{Introduction}

Concerns about children's health, activity and fitness status have been reported by academics, professionals and the media. Government officials and health and PE professionals undoubtedly feel under pressure to react to such concerns, with one proposed response being to focus on and test young people's fitness.

This paper describes the purpose, methods and findings of a commissioned feasibility study to determine if there is a need and whether it is cost effective and practical to carry out a research project to establish the fitness levels of Welsh children.

By way of background, the tender for the contract to conduct the feasibility study stated:

Our extensive background in children's exercise and health' means that we are well aware that the issue of fitness testing in children has been the topic of much debate in recent years, with varying opinions over the potential value of testing in relation to enhancing children's health, fitness and activity status. In this respect, the establishment of clear recommendations of the issue, based on a comprehensive review of the research evidence, is clearly needed' (Health Promotion Division, National Assembly for Wales, February 2003). 
Prior to describing the consequent study and its findings, it is prudent to clarify the meanings of the following terms which are employed by the authors throughout the paper:

Health: a positive state of physical, mental and social well-being; a resource for everyday life, not the objective for living, and a positive concept emphasising social and personal resources as well as physical capacities.

Physical Activity: any bodily movement produced by skeletal muscles that results in energy expenditure; this includes all forms of active play, sport, dance and exercise as well as active transportation (e.g. walking, cycling) and routine habitual activities (e.g. housework and gardening).

Physical Fitness: a set of attributes that people have or achieve that relates to the ability to perform physical activity.

Young People: all individuals aged 5-18 years; the term 'children' generally refers to individuals aged 5-12 years whilst the term 'adolescents' generally refers to teenagers, aged 13-18 years.

The above definitions are consistent with those adopted by Harris $^{1}$ and by Biddle and colleagues ${ }^{2}$ in the development of their policy framework for the Health Education Authority on young people and health-enhancing physical activity. 


\section{Method}

The study was carried out from October 2003 to March 2004. The methodology involved two main parts: a comprehensive review of relevant literature to establish the key findings and issues, and consultation with experts and stakeholders to ascertain their views on the feasibility of fitness testing children in Wales.

The world wide literature search was carried out using metalib (a multidatabase research tool) and focused on the following key areas: physical activity, physical fitness and health in young people; the physical activity status of young people; the physical fitness status of young people; monitoring children's physical fitness; and the role of children's fitness testing in physical activity and fitness promotion. The key findings from 1985 to the present day with respect to the above areas were summarised.

A detailed questionnaire, informed by the findings of the literature review, was designed to elicit information regarding key stakeholders' knowledge, understanding, attitudes and views about the fitness testing of children. The questionnaire comprised three sections and included a mix of closed and open ended questions. The first section sought background information on the respondent's interest, experience and involvement, if any, in fitness testing of children, as well as their awareness of studies of fitness testing on children. The second section sought the respondents' views on fitness testing of children generally, including the perceived benefits, pitfalls, and the role of fitness testing in promoting 
children's health, fitness and activity. The final section focused on their views on the introduction of fitness testing of children in Wales and on fitness testing in the PE curriculum.

The questionnaire was administered to a sample comprising of 35 individuals, predominantly determined from the specification for the study which indicated that key stakeholders/experts should be consulted, including representatives from universities in Wales and England, the PE advisory/inspection service, schools (primary and secondary teachers), physical activity/health promotion, the Sports Council for Wales, and the Welsh Assembly. In addition, seven individuals, all UK researchers of international recognition in the field were included in the sample.

Follow-up interviews were also conducted with a small sample of the key stakeholders/experts. The interview questions were derived from the findings of the literature review and the questionnaire survey. The primary purpose of the follow-up interviews was to clarify, substantiate and enhance data obtained from the questionnaires. Permission was obtained to tape record the interviews and each was transcribed verbatim as soon as possible afterwards by the interviewer.

Due to limited availability and the time constraints of the study, only a small number of individuals were able to participate in a follow-up interview. Six individuals were selected for interview based on a preliminary analysis of the questionnaire findings. In order to gain a representative reflection of the 
experts/stakeholders' views, two individuals who were generally for, one who was generally against, and three who were undecided or neutral about fitness testing children were chosen. This selection broadly reflected the mix of questionnaire responses. The sample included: a head of a university department, a local authority inspector, a teacher/consultant, a university lecturer, and a local authority adviser. The interviews followed a semistructured format, lasted for approximately one hour, and took place in the workplaces of the individuals concerned. All protocols associated with the methodology were in line with the authors' institutional ethical guidelines.

Following data collection, the questionnaires were analysed by quantifying the responses to the closed question items and identifying the common issues and themes reported in the open ended questions. Similarly, the interview data were analysed by the identification of the common themes and consistent issues emerging from the transcripts. The key findings and issues to emerge from the literature were then identified and discussed in relation to the stakeholders/experts' questionnaire and interview data.

\section{Findings from the Literature Review}

The literature revealed that evidence is accumulating that more active children generally display healthier cardiovascular profiles, are leaner and develop higher peak bone mass than their less active counterparts ${ }^{3}$, although the relationships are only weak to moderate ${ }^{4}$. Furthermore, evidence that childhood physical activity may influence adult obesity ${ }^{3}$ and that fitness influences future health is becoming increasingly persuasive. Findings from a 
range of studies ${ }^{5-9}$ suggest that high physical fitness during adolescence and young adulthood is related to a healthy risk factor profile later in adulthood, but that adolescent physical activity levels do not influence cardiovascular disease in later life ${ }^{10}$. There is also moderate to strong evidence that young people's psychological health (e.g. self-esteem) is positively influenced by physical fitness and physical activity ${ }^{11-14}$.

The literature on children's physical activity ${ }^{3,15-33}$ reveal the following key findings and consistent trends:

- Approximately half of boys and two thirds of girls do not meet current physical activity guidelines for young people.

- Polarisation of activity is common, with groups of very active and very inactive youngsters.

- Boys are more active than girls.

- Physical activity declines with age, the teenage years being the time of greatest decline.

- Children's activity patterns are sporadic and highly transitory - most time is spent in low intensity activity with limited experience of sustained periods of moderate to vigorous activity.

- Due to a lack of directly comparable data on young people's physical activity, it cannot be firmly established whether young people's physical activity has declined over previous generations. 
A similar summary of the key findings and trends from reviews of laboratory based fitness tests ${ }^{22,35-40}$ involving children indicate that:

- Young people show a progressive, almost linear increase in peak $\mathrm{VO}_{2}$ with age, although some studies show that from about 14 years, girls' peak $\mathrm{VO}_{2}$ levels off or declines.

- With body size appropriately controlled for, boys' peak $\mathrm{VO}_{2}$ increases through childhood and adolescence and into early adulthood, whilst girls' increases into puberty and then levels off.

- Whilst data are limited, evidence indicates that maturation induces increases in peak $\mathrm{VO}_{2}$ in both sexes, independent of those explained by body size, body fatness and age.

- Boys' peak $\mathrm{VO}_{2}$ is higher than girls' at least from late childhood, and there is a progressive divergence in boys' and girls' values during the teenage years.

A further interesting finding is that there is limited evidence to suggest that low levels of aerobic fitness are common amongst children. For example, analysis of robust fitness test data revealed that only about two per cent of young people could be classified as 'at risk' (i.e. with a peak $\mathrm{VO}_{2}$ below $35 \mathrm{ml} . \mathrm{kg}^{-1} \cdot \mathrm{min}^{-1}$ for boys and 30 for girls $)^{40-42}$ whilst other studies reported none below the 'health risk' threshold ${ }^{22,43}$. Furthermore, neither is there rigorous scientific evidence to suggest that young people's aerobic fitness has declined over the last 50 years ${ }^{22,35,38,45}$. However, it is noted that data collected more recently via field tests within the Sportslinx Project in Liverpool are suggesting 
that aerobic fitness (as measured by the $20 \mathrm{~m}$ Multi-Stage shuttle run test) has decreased by over 15\% in girls and 19\% in boys aged 9-10 years over six years, and decreased by over $13 \%$ in boys and $21 \%$ in girls aged $11-12$ years over a three year period ${ }^{33,46}$.

Having said this, laboratory based assessments are generally assumed to provide more accurate measures of children's fitness than field tests but they are not without their disadvantages ${ }^{38,46-47}$ and, due to cost and practicality, their use is clearly limited on a large scale. Physical fitness testing in the field which typically involves the administration of a battery of tests to evaluate different components of fitness ${ }^{49}$ tends to be even more problematic. Formal fitness test batteries have been devised ${ }^{50}$ which have a number of similarities $^{51-53}$. The following advantages and disadvantages associated with field tests have been identified ${ }^{50-52,54-62}$, some of which also apply to laboratory based fitness tests.

Advantages: 
- The tests are generally easy to administer and time efficient.

- The tests are relatively safe and involve minimal equipment and low cost.

- There have been advances in recent years in the development of physical fitness tests for children and the scientific evidence supporting these tests.

- There is increasing emphasis on the evaluation of health-related fitness components, and a shift from testing in isolation, to an educational programme with testing as an integral part.

- $\quad$ Many physical fitness programmes include test manuals, curricular guidelines and instructional materials to assist the user/teacher, and some programmes have computerized feedback systems.

Disadvantages:

- The appropriateness of some fitness tests for use with children is questionable (e.g., the Multistage Fitness Test was developed predominantly for use with elite, adult populations).

- Children's metabolic, cardiopulmonary, thermoregulatory, and perceptual responses to exercise are different from those of adults and a different approach may therefore be required in administering tests to children.

- Field tests provide only a crude measure of an individual's physical fitness and are not considered suitable for the assessment of single, basic, physiological functions. 
- There are concerns about the reliability and validity of some fitness tests for use with children which stem from the fact that many factors influence children's performance on fitness tests (e.g. heredity, maturation, motivation, environment/test conditions; lifestyle; test protocol/procedures; and intellectual and mechanical skill at taking the test).

- There is some debate over and limitations in the practice of applying norm and/or criterion referenced standards ${ }^{37,63-64}$.

Indeed, even limitations in the methodologies adopted in national fitness surveys and consequently the validity of their findings have been widely acknowledged $^{50,59,61,65-69}$. Perhaps as a consequence, a review of national fitness surveys ${ }^{70-77}$ reveals a gradual shift in emphasis over the years from a focus on physical fitness to physical activity, and other lifestyle behaviours. Furthermore, average scores on various fitness test items tend to have been reported, with no interpretation of their meaning to and/or implications for children's health which implies limited value in terms of influencing policy and practice.

The numerous limitations associated with measuring children's fitness suggest that much of the data generated are not capable of rigorous interpretation. In particular, Armstrong and colleagues ${ }^{78-79}$ claim that fitness tests simply determine the obvious, at best only distinguishing the mature and/or motivated from the immature and/or unmotivated. 
With respect to the role of fitness testing children, a broad range of issues have been raised in the literature $50,52,59,61,65-69$. Firstly, a number of paradoxes relating to fitness testing have been reported ${ }^{68-69}$. For example, fitness tests purport to assess health-related physical fitness yet do not provide any clinical measures of health status (e.g., blood pressure) and they emphasise safe healthy practice yet some involve children performing tests which violate healthy behaviour (e.g. exercising to exhaustion).

A second key issue is that it is often assumed that fitness in children is primarily a reflection of the amount of activity performed, and that those who score high on fitness tests are active and those who do not are inactive ${ }^{57}$. However, these assumptions are inaccurate as the relationship between fitness and physical activity is low among children $^{37,57}$. Thus, there is concern that an active child who scores poorly on a test may become disappointed, disillusioned, demotivated and 'turned off' activity because he/she feels it does not 'pay off', whilst an inactive child who scores well may be delighted with the outcome, conclude that everything is fine when it is not, and consequently may not be motivated to change ${ }^{80}$.

A third important consideration is how test procedures affect the social, emotional, and attitudinal values of young people towards activity ${ }^{69,81}$. Concern has been expressed that fitness testing may be counterproductive to the promotion of active lifestyles in young people ${ }^{56,61,82}$. Indeed, Rowland ${ }^{61}$ believes that fitness tests are anti-ethical to the goal of promoting physical activity in children in so far as they can be demeaning, embarrassing and uncomfortable for children (often those about whom there is most concern), and may reinforce the notion that exercise is competitive and unpleasant. 
Others agree that testing done improperly may turn many youngsters 'off' rather than 'on' to activity, and should therefore be discontinued ${ }^{56,82}$.

Only limited attention has been paid to the motivational effects of fitness testing on children or children's perspectives of, or knowledge and/or attitudes towards fitness tests $^{83-84}$. Whitehead \& Corbin $^{85}$ found that intrinsic motivation increased as a result of positive feedback after a fitness test but decreased following negative feedback. Goudas, Biddle \& Fox ${ }^{86}$ concluded that the effects of fitness testing are complex and that motivational enhancement following testing cannot be taken for granted. Likewise, the Physical Education Association ${ }^{59}$ noted that there is no hard evidence that fitness tests motivate individuals and suggest that in parallel areas of education, there is supportive evidence that tests only motivate those who do well. Hopple \& Graham $^{87}$ revealed that children generally showed little or no understanding of why they were being asked to complete a mile run test and many disliked taking it, viewing it as a painful, negative experience to be either actively or passively 'dodged.' Another study involving adolescents revealed that they viewed fitness testing unfavourably and as a major contributor to negative attitudes towards $\mathrm{PE}^{88}$.

A further concern is that the administration of fitness tests could lead to more attention being given to product related issues such as 'fitness' and 'performance' than to process-oriented issues such as 'health' and 'physical activity' behaviour ${ }^{81,89}$. From a public health and physical activity promotion perspective, it has been argued that the goal should be to influence the 'process' of being active rather than the 'product' of being fit $^{21,61,80-81,90}$ as, in contrast to physical fitness (an attribute), increased physical activity (a behaviour) is an outcome that can be accomplished by all children 
regardless of ability (or disability) or personal interests, and will further benefit those young people who need it most.

Unfortunately, the literature does not resolve the question as to whether fitness or activity is more important to health ${ }^{3}$. Nonetheless, the evidence that fitness is related to health itself, without being mediated by physical activity, is becoming increasingly persuasive. This could lead some to conclude that it may be better to focus on physical fitness rather than physical activity in youth. However, this association may in part be genetically determined and be independent of activity. For instance, a high fit individual could have inherited good health and conversely a low fit individual could be unfortunate to have poorer health. An alternative but not mutually exclusive explanation might be that fitness acts as a marker for high activity, which might not only improve cardiovascular function, but also promote changes in other health indicators (e.g., lower blood pressure) ${ }^{3}$.

The literature reveals mixed views on the place of fitness testing within the PE curriculum. For example, Pate ${ }^{91}$ considers that too often tests have either been an almost irrelevant adjunct or they have dominated programmes. The amount of curriculum time spent on fitness testing without necessarily positively influencing young people's activity levels or their attitudes towards physical activity has been criticised $^{81,89}$ and it could be argued that the time spent on testing may be at the expense of time spent on more useful activity promoting activities, and of developing relevant knowledge and understanding. Certainly, administering fitness tests simply to acquire data, without attention to its' educational role is not advised ${ }^{92}$. 
Concerns have also been expressed over the possible inappropriate or undesirable use of fitness test scores, for example, using them in schools to grade children's achievement, to evaluate teacher competence, or as a measure of the success of an institution or programme ${ }^{80,82}$. Employing fitness tests for such purposes has been challenged ${ }^{80} 82$, with warnings that it could have potential negative consequences such as a loss of interest in PE and physical activity, teaching to the test, student and teacher cheating on fitness tests, and undermining the confidence of students who find that, even with effort, they cannot achieve the fitness goals necessary to achieve good grades or to meet teacher expectations ${ }^{80}$.

Corbin, Pangrazi \& Welk ${ }^{82}$ are of the view that fitness testing might survive only if it can be shown that it promotes the right philosophy. In other words, testing can be a valuable component of an educational programme if it encourages positive attitudes towards health-related fitness, increases understanding of the principles underlying health-related fitness, and promotes a lifetime commitment to physical activity ${ }^{59,82}$.

Given the limitations and issues highlighted within the literature, key recommendations have been made about the use of fitness testing in children ${ }^{44,65,82,92-97}$. These include:

- Test batteries should be child-centred and include developmentally appropriate exercises. Tests designed for adults should be avoided 
or modified. Personal improvement over time should be the focus, not comparison with others.

- The development and maintenance of lifelong activity habits should be addressed and activity promotion measures included (e.g., monitoring activity; raising awareness and providing access to activity opportunities; goal setting, self-evaluation) alongside testing (as it should not be assumed that fitness testing will necessarily increase pupils' activity levels).

- Fitness testing should be positive, meaningful and individualised with personalised baseline scores and feedback from which to improve. Testing should not be administered at the expense of lowering an individual's self-esteem or confidence.

- Fitness testing should promote learning, and health-related learning concepts should be delivered during the fitness testing process (e.g., explaining the relevance of and how to improve each component).

- Fitness test results should be communicated and used with children in a meaningful way that promotes affective and cognitive learning. Any standards employed in interpreting scores should be explained and criterion referenced (as opposed to normative) as these are attainable by most children and reinforce the fitness-health link and the notion that one can be fit without being an elite athlete.

- In the case of more formal testing, data from which will be publically reported, tests should only be performed: 
1. when appropriate ethical approval has been obtained including acquiring parental consent and children's assent, making clear who has access to data and how it is to be used;

2. by individuals who are 'Criminal Record Bureau' checked, are trained to deliver testing to a high degree of accuracy and who understand key issues such as test sensitivity and validity; the appropriateness of same sex testers is also an important issue for consideration.

\section{Findings from Questionnaires and Interviews with Experts and Stakeholders}

All respondents expressed some concerns about children's health, fitness and activity and considered that action was required; however, views varied as to the urgency of this and the precise nature of the action needed. Examples of the responses included:

I have a major concern about the fitness of children in Wales. I believe we need to introduce fitness testing and allied fitness programmes as soon as possible; it may be that the fitness testing will show our children to be the fittest in the UK but somehow I doubt it - but more to the point, at the moment we don't know how we compare (PE Consultant) 
If you talk to doctors, they are saying the same thing, that these children are fatter, there is elevated blood pressure, diabetes is increasing, all major medical problems which can only be resolved if lifestyles and inactivity... are addressed (PE Adviser).

If we do something radical, something big, something expensive...then, it can be a real turning point in Welsh life and Welsh culture. We are not a healthy nation and we need to change that. We need to start with children....we have a golden opportunity to address...this critical issue of their health and fitness status...(PE Adviser).

However, some confusion was evident amongst the stakeholders about the meanings of the concepts 'health', 'fitness' and 'activity', and about the relationships between them; terms were used interchangeably suggesting they were synonymous. The following quotations exemplify this point:

In terms of the health of our nation, we really do need to look at the fitness of our youngsters very, very seriously...(PE Teacher).

Fitness testing is very important to gain evidence and facts about health (PE Teacher). 
We certainly have to raise the profile of fitness in our youngsters, and until we do that we're not going to move them towards an active healthy lifestyle, one where fitness is important to them (PE Adviser).

All experts and most stakeholders had experience of fitness testing children, but the majority of stakeholders had limited knowledge of associated research and literature. There were mixed views on the fitness testing of children; potential benefits that were identified included the provision of baseline data to inform policy, and potential pitfalls included possible negative effects on children and the limited validity and reliability of the data. The diverse nature of the views are exemplified by the following quotations:

Testing can establish a baseline from which trends can be studied and one can evaluate the effect of fitness and activity on key health indicators (PE Lecturer).

Tests can provide baseline assessments to monitor individual progress and improvement (PE Teacher).

Some children hate fitness testing due to public results, fear of 'looking daft' in front of peers and fear of failure (PE Teacher).

PE teachers who use fitness tests regularly...should be encouraged to stop. Children often hate and dread them, they don't tell us very much, and why should children be forced to endure them? (PE Consultant). 
Even in a well-equipped sports science laboratory using 'scientific' tests, one might consider the error to be around $10 \%$. In the field situation using simpler methods...the error is likely to be huge (PE Lecturer).

There were diverse views about large scale fitness testing of children, and the usefulness of having fitness testing data on Welsh school children, although many considered that it might be helpful to track the fitness of Welsh children over time. These views are reflected in the following comments:

Large-scale fitness testing will enable us to develop future policy based on relevant information, will raise the profile of the physical fitness of children in Wales, and provide targets for young people to develop their own physical fitness (PE Consultant).

I think it would be misguided and a backward looking step which will do much to discourage children from exercise; I believe the scientific evidence (physiological and psychological) points away from fitness testing. Fitness testing is something that at first glance is appealing to the public and politicians and seems to be a simple step towards improving health, but once consideration is given to the issue in a little more depth, the problems become clear (PE Lecturer). 
We don't know where we are at the moment with regard to the fitness of children in Wales...we certainly don't know where we stand now in comparison with the past so I would hope that this might be the beginning of something in terms of having a definitive baseline from where we can start to move on (PE Teacher).

Many, however, were not convinced about the use of fitness testing to promote health, and questioned the role of fitness testing in the promotion of activity. Most considered it inappropriate to use fitness testing data to evaluate national programmes. Typical responses included:

Fitness testing would scare half the population to death and most would hate the testing procedure...I don't feel it would be useful as 'health' is what should be promoted, not particularly 'fitness' to the majority of people (PE Consultant).

Health isn't really about fitness and I think it would give the wrong message if we promoted health as being 'fit'. This would put a lot of people off trying to be healthy if they thought they'd have to have a high fitness level to be healthy (PE Adviser).

Physical activity can be promoted without having to fitness test children; enjoyment is more important (PE Teacher). 
I think we would mislead teachers about the purpose of these programmes; they are about 'sport for all', enjoyment and participating, not about getting fit (PE Consultant).

There were mixed views on the place of fitness testing within the PE curriculum. Some were concerned that fitness testing in the PE curriculum would 'use up' valuable PE time and detract teachers from an educational focus; however, others considered that fitness testing could be used to improve children's understanding of health, fitness and activity, and encourage them to be more responsible for health-related lifestyle decisions. The range of views are demonstrated in the following quotations:

We might end up with physical activity replacing physical education in a programme because of a fundamental misunderstanding of what it's all about, that is my concern... if physical education becomes physical activity because we need to have the children more fit, then we are back to the days where the teacher would stand there and say 'right everybody, run and stop....' OK, they'd have a lot of physical activity and they probably would be fitter, but they certainly wouldn't be more physically educated (PE Teacher).

Fitness testing in schools is of little value and curricular time could and should be better spent (Expert). 
Fitness testing can be motivational if taught in the right way within the right context; it can motivate some children into 'beating' their previous scores (PE Adviser).

Fitness testing can be used as a lever to stimulate interest in exercise and can direct children towards a healthy lifestyle (PE Consultant).

All participants were of the view that any future study of children's fitness should be on a large scale, longitudinal, and conducted by researchers, as opposed to teachers in schools. Further, they felt that the study should have a broad focus, investigating health, fitness and activity, in addition to other health behaviours such as eating habits. Example responses included:

Testing should be done under the auspices of a controlling group....it could be within one University or could be a group of people from different universities, but it has to be done in a way in which we can be confident about the quality of the data (PE Lecturer).

Let's collect some data on what the lifestyle of children is actually like at the moment... what do they do per day, what do they eat per day, how much involvement do they have with parents/without parents, where does most of their physical activity take place...let's get a picture (PE Consultant). 


\section{Discussion}

The literature suggests that stakeholders and experts were right in their belief that physical activity and physical fitness in children provide health benefits. Furthermore, whilst the literature indicates that the association between childhood fitness and activity and children's current or future health can not as yet be described as empirically strong, positive associations do exist and the evidence for a beneficial effect is mounting. Until more substantial research evidence becomes available, it would therefore seem unwise to conclude that lack of more definitive data on the health benefits of youth physical activity and physical fitness means that neither is important for their health.

PE and health professionals' concerns about children's physical activity levels are validated by the literature in that a sizeable proportion of children (half of girls and a third of boys) do not meet physical activity recommendations and are leading sedentary lifestyles which, over time, will negatively affect their health status.

However, the literature indicates that some stakeholders' concerns about children's physical fitness may be unfounded. Possible reasons for the misconceptions amongst stakeholders about children's fitness appear to stem from confusion about the meaning of the terms 'health', 'activity' and 'fitness', the relationships between them, and how each are monitored. Indeed, the commonly held view and argument in favour of fitness testing children, namely that there are concerns over widespread low levels of fitness and the possible health consequences in children, are based on numerous myths such as: low levels of fitness are common amongst children; children's 
fitness has declined in recent years; children who perform well on fitness tests are the most active; and fitness testing children will increase their activity levels. These myths need to be dispelled and professionals helped to better understand these concepts and the relationships between them. Individuals involved in fitness testing children would benefit from guidance and training in this respect.

The stakeholders clearly had mixed views on the desirability and usefulness of fitness testing children, all of them recognising some possible limitations of fitness testing. As to be expected, the 'experts' were well informed on this subject, and consequently much more vociferous in their view that, due to the methodological and other limitations, there would be little to be gained from national fitness testing of school children.

Stakeholders had doubts about the role of fitness testing in the promotion of health and activity which seem well founded given the range of issues identified in the literature over the use of fitness tests with children. The literature supports some stakeholders and experts' views that fitness testing might negatively affect some young people. Indeed, this partly explains the mixed views held by stakeholders on the place of fitness testing within the PE curriculum. Given the issues, concerns and limitations identified in the literature, it is probably of little surprise that a few stakeholders had abandoned fitness tests in favour of alternative methods of assessing children such as monitoring their knowledge, understanding, and attitudes towards 
physical activity and health, and their physical activity and other health behaviours.

However, the literature also presents recommendations to help ensure that any fitness testing used within the school curriculum helps to increase children's knowledge and understanding of health, activity and fitness, to promote positive attitudes towards an active way of life, and to increase pupils' involvement in healthy, active lifestyles. Teachers and others involved in testing children clearly need to be aware of these recommendations and supported to help them achieve such objectives.

\section{Conclusion}

As the measurement of children's fitness is fraught with difficulties and the large scale national fitness surveys conducted to date have revealed little meaningful information on children's fitness levels, or certainly limited information that appears to have been used to inform policy and practice, the feasibility study concluded that no study on Welsh children should focus solely on monitoring fitness as this would be inappropriate and misguided.

However, a broader 'lifestyle orientated' research project prioritising the promotion and monitoring of physical activity levels in young people was considered desirable as, unlike fitness (an attribute), activity (a behaviour) is an outcome that can be achieved by all children. In addition, professionals working with children and young people should be offered professional development opportunities to ensure that the health, activity and fitness 
programmes they plan for children help them contribute to, rather than hinder, progress towards a more active, healthier young population. 


\section{References}

1. Harris J. Health-Related Exercise in the National Curriculum. Key Stages 1 to 4. Leeds: Human Kinetics, 2000.

2. Biddle S, Sallis J, Cavill N. (Eds) (1998). Young and Active? Young People and Health-enhancing Physical Activity - Evidence and Implications. London: Health Education Authority.

3. Boreham C, Riddoch C. The physical activity, fitness and health of children. Journal of Sports Science 2001; 19: 915-929.

4. Twisk JWR. Physical activity, physical fitness and cardiovascular health. In: Armstrong N, \& Van Mechelen, W. (eds). Paediatric Exercise Science and Medicine. Oxford: Oxford University Press, 2000, 253-263.

5. Twisk JWR, Kemper HCG, Van Mechelen W. The relationship between physical fitness and physical activity during adolescence and cardiovascular disease risk factors at adult age: The Amsterdam Growth and Health Longitudinal Study. International Journal of Sports Medicine 2002; 23 (supplement): S8-S14.

6. Janz KF, Dawson JD, Mahoney LT. Increases in physical fitness during childhood improves cardiovascular health during adolescence: The Muscatine Study. International Journal of Sports Medicine 2002; 23 (supplement): S15-S21. 
7. Boreham C, Twisk J, Neville C, Savage M, Murray L, Gallagher A. Associations between physical fitness and activity patterns during adolescence and cardiovascular risk factors in young adulthood: The Northern Ireland Young Hearts Project. International Journal of Sports Medicine 2002; 23 (supplement): S22-S26.

8. Hasselstrom H, Hansen SE, Froberg K, Andersen LB. Physical fitness and physical activity during adolescence as predictors of cardiovascular disease risk in young adulthood: Danish Youth Sports Study: An eight-year follow-up study. International Journal of Sports Medicine 2002; 23 (supplement): S27S31.

9. Lefevre J, Philippaerts R, Delvaux K, Thomis M, Claessens AL, Lysens R, et al. Relation between cardiovascular risk factors at adult age, and physical activity during youth and adulthood. The Leuven Longitudinal Study on Lifestyle, Fitness and Health. International Journal of Sports Medicine 2002; 23 (supplement): S32-S38.

10. Twisk JWR, Kemper HCG, Van Mechelen,W. Prediction of cardiovascular disease risk factors in later life by physical activity and physical fitness in youth: General comments and conclusions. International Journal of Sports Science 2002, 23 (supplement): S440-S50. 
11. Biddle S. Exercise and psychosocial health. Research Quarterly for Exercise and Sport 1995; 66: 292-297.

12. Calfas KJ, Taylor C. Effects of physical activity on psychological variables in adolescents. Pediatric Exercise Science 1994; 6: 406-423.

13. Mutrie N, Parfitt G. Physical activity and its link with mental, social and moral health in young people. In: Biddle S, Sallis J, Cavill N. (eds). Young and Active? Young People and Health-enhancing Physical Activity - Evidence and Implications. London: Health Education Authority, 1998; 49-68.

14. Tortolero SR, Taylor WC, Murray NG. Physical activity, physical fitness and social, psychological and emotional health. In: Armstrong N, Van Mechelen W. (eds). Paediatric Exercise Science and Medicine. Oxford University Press, 2000, 273-293.

15. Cale L, Almond L. Physical activity levels of young children: a review of the evidence. Health Education Journal 1992; 51(2): 94-99.

16. Cale L, Almond L. Physical activity levels of secondary-aged children: a review. Health Education Journal 1992; 51(4): 192-197.

17. Cale L, Almond L. Children's activity levels: a review conducted on British children. Physical Education Review 1992; 15(2): 111-118. 
18. Pate RR, Long BJ, Heath G. Descriptive epidemiology of physical activity in adolescents. Pediatric Exercise Science 1994; 6: 434-447.

19. Sallis JF. Epidemiology of physical activity and fitness in children and adolescents. Critical Reviews in Food Science and Nutrition 1993; 33: 403408.

20. Sallis JF, Owen N. The descriptive epidemiology of physical activity participation by youth. In: Sallis J, Owen N. (eds). Physical Activity and Behavioural Medicine. Thousand Oaks: Sage Publications, 1999, 102-106.

21. Riddoch C, Boreham CAG. The health-related physical activity of children. Sports Medicine 1995; 19(2): 86-102.

22. Armstrong N, Van Mechelen W. Are young people fit and active? In: Biddle S, Sallis J, Cavill N. (eds). Young and Active? Young People and Health-enhancing Physical Activity - Evidence and Implications. London: Health Education Authority, 1998, 69-97.

23. Cavill N. Children and Young People - The Importance of Physical Activity. A paper published in the context of the European Heart Health Initiative. Brussels: European Heart Network, 2001.

24. King AJC, Coles B. The Health of Canada's Youth. Canada: Ministry of Health and Welfare, 1992. 
25. Department of Health and Human Services, Centers for Disease Control and Prevention. Physical Activity and Health: A Report of the Surgeon General. Atlanta, GA: Author, 1996.

26. World Health Organization. Health and Health Behaviour Among Young People WHO Policy Series: Health Policy for Children and Adolescents, Issue 1, International Report. Copenhagen, Denmark: WHO, 2000.

27. Sport England. Young People and Sport. National Survey 1999.

London: Author, 2001.

28. Joint Health Surveys Unit. Health Survey for England: The Health of Young People 1995-1997. London: HMSO, 1998.

29. Balding J. Young People in 2000. Exeter: Schools Health Education Unit, 2001.

30. Gregory J, Lowe S. National Diet and Nutrition Survey: Young People aged 4 to 18 years. London: The Stationary Office, 2000.

31. Sports Council for Wales. Sports Update 45, Widening the Net: Young People's Participation in Sport 1999/2000. SCW: Cardiff, 2001. 
32. Sports Council for Wales. Swings and Roundabouts? Primary School Children's Participation in Sport. SCW: Cardiff, 2001.

33. Taylor, S., Lamb, E., Hackett, A., Stratton, G. (2003). Liverpool Sportslinx Project 01-03. Report on the health and fitness of Liverpool primary and secondary school children. Liverpool City Council, Education, Libraries and Sport Services.

34. Armstrong N, Welsman JR. Assessment and interpretation of aerobic fitness in children and adolescents. Exercise and Sports Sciences Reviews 1994; 22: 435-476.

35. Rowland TW. Declining cardiorespiratory fitness in youth: fact or supposition? Pediatric Exercise Science 2002; 14: 1-8.

36. Welsman J, Armstrong N. The measurement and interpretation of aerobic fitness in children: current issues. Journal of the Royal Society of Medicine 1996; 89: 281-285.

37. Armstrong N, Welsman J. Young People and Physical Activity. Oxford University Press, 1997.

38. Armstrong N, Welsman J. Aerobic fitness. In: Armstrong N, Van Mechelen W. (eds). Paediatric Exercise Science and Medicine. Oxford University Press, $2000,65-75$. 
39. Armstrong N, Welsman JR. Development of aerobic fitness during childhood and adolescence. Pediatric Exercise Science 2000; 12: 128-149.

40. Armstrong N, Balding J, Gentle P, Kirby B. Estimation of coronary risk factors in British school children: a preliminary report. British Journal of Sports Medicine 1990; 24: 61-66.

41. Armstrong N, Williams J, Balding J, Gentle P, Kirby B. The peak oxygen uptake of British children with reference to age, sex, and sexual maturity. European Journal of Applied Physiology 1991; 62: 369-375.

42. Armstrong N, Kirby B, McManus A, Welsman J. Physical activity patterns and aerobic fitness among pre-pubescents. European Physical Education Review 1996; 7: 19-29.

43. Armstrong N, Kirby BJ, McManus AM, Welsman JR. Aerobic fitness of pre-pubescent children. Annals of Human Biology 1995; 22: 427-441.

44. Corbin CB, Pangrazi RP. Are American children and youth fit? Research Quarterly for Exercise and Sport 1992; 63(2): 96-106.

45. Blair SN. Youth fitness: Directions for future research. In: Cheung LWY., Richmond JB. (eds). Child Health, Nutrition and Physical Activity. Champaign, IL: Human Kinetics, 1995, 147-152. 
46. Lamb, E., Boddy, L., Hackett, A., Stratton, G., Taylor, S., Watson, P. (2005). Putting Children First. Sportslinx Sport, Nutrition, Health, Education. Childhood fitness in Liverpool. Where do we go from here? Liverpool City Council, Education, Libraries and Sport Services.

47. Blimkie CJR, Macauley D. Muscle strength. In: Armstrong N, Van Mechelen W. (eds). Paediatric Exercise Science and Medicine. Oxford University Press, 2000, 23-36.

48. Claessens AL, Beunen G, Malina RM. Anthropometry, physique, body composition and maturity. In: Armstrong N, Van Mechelen W. (eds). Paediatric Exercise Science and Medicine. Oxford University Press, 2000, 1121.

49. American College of Sports Medicine. (ACSM). Exercise testing and prescription for children, the elderly, and pregnant women. In: ACSM's Guidelines for Exercise Testing and Prescription. Sixth edition. Lippincott Williams \& Wikins, 2000, 217-234.

50. Fox K, Biddle S. Health related fitness testing in schools: Introduction and problems of interpretation. The Bulletin of Physical Education 1986; 22: 54-64. 
51. Pate RR. Fitness testing: current approaches and purposes in physical education. In: Pate RR, Hohn RC. (eds). Health and Fitness Through Physical Education. Champaign, III: Human Kinetics, 1994, 119-127.

52. Safrit M. The validity and reliability of fitness tests for children: A review. Pediatric Exercise Science 1990; 2: 9-28.

53. The Cooper Institute for Aerobics Research. FITNESSGRAM. Test Administration Manual, Second Edition. Champaign, III: Human Kinetics, 1999.

54. Bar-Or O. Importance of differences between children and adults for exercise testing and exercise prescription. In: Skinner JS. (ed). Exercise Testing and Prescription for Special Cases. Second edition. Lea \& Febiger, 1993, 57-74.

55. Bouchard C, Dionne FT, Simoneau J, Boulay,M. Genetics of aerobic and anaerobic performances. Exercise and Sport Sciences Reviews 1992; 20: 27 58.

56. Docherty D, Bell R. Fitness testing: counterproductive to a healthy lifestyle? CAHPER Journal 1990; 56(5): 4-8.

57. Pangrazi RP. Promoting physical activity for youth. The ACHPER Healthy Lifestyles Journal 2000; 47(2): 18-21. 
58. Pangrazi RP, Corbin CB. Age as a factor relating to physical fitness test performance. Research Quarterly for Exercise and Sport 1990; 61(4): 410414

59. Physical Education Association (PEA). Health related fitness testing and monitoring in schools. A position statement on behalf of the PEA by its fitness and health advisory committee. British Journal of Physical Education 1998; 19(4/5): 194-195.

60. Rice MH, Howell CC. Measurement of physical activity, exercise and physical fitness in children: issues and concerns. Journal of Pediatric Nursing 2000; 15(3): 148-156.

61. Rowland TW. The horse is dead; let's dismount. Pediatric Exercise Science 1995; 7: 117-120.

62. Safrit MJ, Looney MA. Should the punishment fit the crime? A measurement dilemma. Research Quarterly for Exercise and Sport 1992; 62: 24-127.

63. Cureton KJ. Physical fitness and activity standards for youth. In: Pate RR, Hohn RC. (eds). Health and Fitness Through Physical Education. Champaign, III: Human Kinetics, 1994, 129-136. 
64. Cureton KJ, Warren G. Criterion-referenced standards for youth healthrelated fitness tests: a tutorial. Research Quarterly for Exercise and Sport. 1990; 61: 7-19.

65. American College of Sports Medicine. (ACSM). Opinion statement on physical fitness in children and youth. Medicine and Science in Sport and Exercise 1988; 20(4): 422-3.

66. Armstrong N. A critique of fitness testing. In: Biddle S. (ed). Foundations of Health Related Fitness in Physical Education. London: Ling Publishing House, 1987, 19-27.

67. Armstrong N. Is fitness testing either valid or useful? British Journal of Physical Education 1989; 20: 66-67.

68. Cale L, Harris J. The benefits of health-related physical education and recommendations for implementation. The Bulletin of Physical Education 1998; 34(1): 27-41.

69. Seefeldt V, Vogel P. Physical fitness testing of children: A 30-year history of misguided efforts. Pediatric Exercise Science 1989; 1: 295-302.

70. Ross JG, Gilbert GG. The National Children and Youth Fitness Study. A Summary of Findings. Journal of Physical Education, Recreation and Dance 1985; 56: 45-50. 
71. Ross JG, Pate RR. The National Children and Youth Fitness Study II. A Summary of Findings. Journal of Physical Education, Recreation and Dance 1987; 58: 51-56.

72. US Department of Health and Human Services. 1985 President's Council on Physical Fitness and Sports Youth Survey. Washington, DC: US Government Printing Office, 1986.

73. Shephard RJ. Fitness of a Nation: Lessons from the Canada Fitness Survey. In: Hebbelinck M, Shephard RJ. (eds). Medicine and Sports Science. New York: Karger, 1986.

74. Stephens T, Craig Cl. The Well Being of Canadians: Highlights of the Campbells' Survey. Ottawa: Canadian Fitness and Lifestyle Research Institute, 1988.

75. Torrance GM. Campbell Survey Results for Youth. Fitness Development Unit Fitness Canada, 1991.

76. Pyke J. Australian Health and Fitness Survey. Adelaide, Australia: ACHPER, 1987.

77. Division of Physical and Health Education. Northern Ireland Fitness Survey. The Fitness, Physical Activity, Attitudes and Lifestyles of Northern 
Ireland Post Primary School Children. Belfast: Division of Physical and Health Education, The Queen's University of Belfast, 1990.

78. Armstrong N. The assessment of health-related fitness in schools. In: Darmody M, O'Donovan G. (eds). Physical Education at the Crossroads. Limerick: PEAI, 1995, 44-48.

79. Armstrong N, Biddle S. Health-related physical activity in the national curriculum. In: Armstrong N. (ed). New Directions in Physical Education, Volume 2, Towards a National Curriculum. Champaign, IL: Human Kinetics, 1992, 71-110.

80. Corbin CB. Physical activity for everyone: what every physical educator should know about promoting lifelong physical activity. Journal of Teaching in Physical Education 2002; 21: 128-144.

81. Cale L, Harris J. National fitness testing for children - issues, concerns and alternatives. The British Journal of Teaching Physical Education 2002; 33(1): 32-34.

82. Corbin CB, Pangrazi RP, Welk GJ. A response to 'The horse is dead; let's dismount.' Pediatric Exercise Science 1995; 7: 347-351. 
83. Fox KR, Biddle SJH. The use of fitness tests: educational and psychological considerations. Journal of Physical Education Recreation and Dance 1988; 59(2): 47-53.

84. Jackson JA. Fitness testing: student and teacher perspectives. FAHPERD Journal of Health, Physical Education, Recreation and Dance 2000; 38(3): 29-31.

85. Whitehead JR, Corbin CB. Youth fitness testing: the effect of percentilebased evaluative feedback on intrinsic motivation. Research Quarterly for Exercise and Sport 1991; 62: 225-231.

86. Goudas M, Biddle S, Fox K. Achievement goal orientations and intrinsic motivation in physical fitness testing with children. Pediatric Exercise Science 1994; 6: 159-167.

87. Hopple C, Graham G. What children think, feel and know about physical fitness testing. Journal of Teaching in Physical Education 1995; 14(4): 408-417.

88. Luke MD, Sinclair GD. Gender differences in adolescents' attitudes toward school physical education. Journal of Teaching in Physical Education 1991; 11: 31-46. 
89. Harris J, Cale L. How healthy is school PE? A review of the effectiveness of health-related physical education programmes in schools. Health Education Journal 1997; 56: 84-104.

90. Cavill N, Biddle S, Sallis JF. Health enhancing physical activity for young people: Statement of the United Kingdom Expert Consensus Conference. Pediatric Exercise Science 2001; 13: 12-25.

91. Pate RR. The case for large-scale physical fitness testing in American youth. Pediatric Exercise Science 1989; 1: 290-294.

92. Harris J. Health-Related Exercise in the National Curriculum. Key Stages 1 to 4. Leeds: Human Kinetics, 2000.

93. American Alliance for Health, Physical Education, Recreation and Dance (AAHPERD). Physical Education for Lifelong Fitness. The Physical Best Teachers' Guide. Champaign, IL: Human Kinetics, 1999. 
94. American Alliance for Health, Physical Education, Recreation and Dance (AAHPERD). Physical Best Activity Guide. Secondary Level. Champaign, IL: Human Kinetics, 1999.

95. American Alliance for Health, Physical Education, Recreation and Dance (AAHPERD). Physical Best Activity Guide. Elementary Level. Champaign, IL: Human Kinetics, 1999.

96. Harris J, Elbourn J. Measure for measure. Does activity and fitness monitoring have a place within physical education? Sports Teacher 1994, Autumn: 11-15.

97. Pate RR, Hohn RC. Health-related physical education - a direction for the $21^{\text {st }}$ century. In Pate RR, Hohn RC. (eds). Health and Fitness Through Physical Education. Champaign, III: Human Kinetics, 1994, 215-217. 